\title{
A case report of endocarditis and spondylitis caused by Brucella melitensis biovar 3
}

Huan Zhang ${ }^{1 \dagger}$, Songsong Xie ${ }^{2,3+}$, Yueli Wang ${ }^{1 \dagger}$, Xiaoli Zhao ${ }^{1}$, Jihai Yi ${ }^{1}$, Zhen Wang ${ }^{1}$, Qi Liu ${ }^{3}$, Xiaoyu Deng ${ }^{1}$, Bingjie Li ${ }^{3}$, Buyun Cui ${ }^{4}$, Yuanzhi Wang ${ }^{5^{*}}$ and Chuangfu Chen ${ }^{{ }^{*}}$

\begin{abstract}
Background: This case report describes the clinical process of a shepherd who suffered brucellosis-related endocarditis (BE) and spondylitis (BS) and was infected with Brucella melitensis biovar 3 (B. melitensis biovar 3).

Case presentation: A 55-year-old male patient was admitted to The First Affiliated Hospital of Shihezi University on October 11, 2018, due to over 3 months of intermittent fever, back pain, and heart trouble. The Rose Bengal Plate test was positive, the standard agglutination test titer for brucellosis was 1/800, and the blood culture was positive for B. melitensis biovar 3. Three instances of transthoracic echocardiography examination at days 1, 25, and 376 after admission to the hospital and magnetic resonance imaging (MRI) and computed tomography (CT) checks at days 5 and 38 revealed that the size of the vegetation on the posterior leaflet of the mitral valve increased from $0.7 \times 1.4$ $\mathrm{cm}$ to $1.2 \times 1.5 \mathrm{~cm}$ and that the left atrium and ventricle were enlarged. The MRI and CT results showed hyperplasia of the second and third vertebra, a cold abscess formed on both sides of the psoas major muscles, and the vertebra hyperplasia became aggravated at a later time point. The patient's situation deteriorated, and heart failure was discovered on October 22, 2019. At the moment of submission of this manuscript, the patient remains in bed at home because of severe debility caused by brucellosis.
\end{abstract}

Conclusions: This is the first reported case of endocarditis combined with spondylitis caused by B. melitensis biovar 3 in a shepherd. Brucellosis infection can cause work-power losses because of misdiagnosis or a lack of proper treatment. Early diagnosis and treatment are essential for a successful outcome.

Keywords: Brucella melitensis biovar 3, Endocarditis, Spondylitis, Shepherd

\section{Background}

Brucellosis is a worldwide zoonotic disease caused by Brucella spp. Humans can be infected by Brucella mainly through the consumption of unpasteurized dairy products, inhalation of infected aerosolized particles, and

\footnotetext{
* Correspondence: wangyuanzhi621@126.com; chuangfu_chen@163.com 'Huan Zhang, Songsong Xie and Yueli Wang contributed equally to this work.

${ }^{5}$ School of Medicine, Shihezi University, Shihezi City 832000, Xinjiang, China ${ }^{1}$ School of Animal Science and Technology, Shihezi University, Shihezi City 832000, Xinjiang, China

Full list of author information is available at the end of the article
}

close contact with infected animals [1]. Brucella infection causes lesions in multiple organs in the human body. The spleen, liver, testis, bone marrow, and reticuloendothelial cells are the most affected, while cardiovascular and osteoarticular involvements, such as endocarditis, myocarditis, and spondylitis, are rare [2]. A total of 44,036 brucellosis cases occurred in China in 2019 according to the latest data released by the China Centers for Disease Control and Prevention (http://www.chinacdc.cn). The Xinjiang Uygur Autonomous Region (XUAR) is one of the leading pastoral areas in China, which is also an epidemic area with

C C The Author(s). 2021 Open Access This article is licensed under a Creative Commons Attribution 4.0 International License, which permits use, sharing, adaptation, distribution and reproduction in any medium or format, as long as you give appropriate credit to the original author(s) and the source, provide a link to the Creative Commons licence, and indicate if changes were made. The images or other third party material in this article are included in the article's Creative Commons licence, unless indicated otherwise in a credit line to the material. If material is not included in the article's Creative Commons licence and your intended use is not permitted by statutory regulation or exceeds the permitted use, you will need to obtain permission directly from the copyright holder. To view a copy of this licence, visit http://creativecommons.org/licenses/by/4.0/ The Creative Commons Public Domain Dedication waiver (http://creativecommons.org/publicdomain/zero/1.0/) applies to the data made available in this article, unless otherwise stated in a credit line to the data. 
high morbidity due to brucellosis [3]. However, only a few studies regarding endocarditis and spondylitis attributable to Brucella have been reported in China, especially in remote regions. This study focuses on a patient living in the XUAR who suffered from brucellosis-related endocarditis (BE) and spondylitis (BS). The manifestations in this patient are described, and the genetic characteristics of the pathogenic agent are analyzed.

\section{Case presentation}

A 55-year-old male shepherd without preexisting diseases began to experience an intermittent fever up to $38-39^{\circ} \mathrm{C}$ and back pain on July 1,2018 . The patient was started on oral cephalosporin for 3 months (self-administered), but his symptoms persisted. The patient was sent to the First Affiliated Hospital of Shihezi University with a normal body temperature at $36.6{ }^{\circ} \mathrm{C}$, where he underwent transthoracic echocardiography (TTE) on October 11, 2018. Vegetation $(0.7 \times 1.5 \mathrm{~cm})$ was discovered on the posterior leaflet of the mitral valve by a TTE examination (Fig. 1a), which caused a mild regurgitation. The serum tube agglutination test (SAT) for Brucella was positive with a titer of 1:800, but the culture result was negative. The blood test results showed that the hemoglobin levels were reduced to $120 \mathrm{~g} / \mathrm{L}$ (see Additional file 1). The levels of platelets, RBC, and albumin were lower than the normal range. However, the levels of globulin and erythrocyte sedimentation rate (ESR) were higher than the normal range (see Additional file 1). A combination of treatment with doxycycline $(200$ $\mathrm{mg} /$ day) and rifampicin $(900 \mathrm{mg} /$ day $)$ was administered to the patient. However, the clinical symptoms were not relieved, and the patient was experiencing a serious backache. The MRI examination revealed that a cold abscess had formed on both sides of the psoas major muscles and the left side of the erector spinae muscle (Fig. 2a), and the CT results indicated hyperplasia of the second and third vertebra (Fig. 2c) on October 15, 2018. The MRI showed a low signal intensity on the T1weighted images and a high signal intensity on the T2- weighted images of the second and third vertebra. Because of financial constraints, the patient refused to undergo surgical treatment. Hence, he was prescribed oral doxycycline $(100 \mathrm{mg} /$ dose, twice a day) and rifampicin $(600 \mathrm{mg} /$ dose, once daily) as recommended by the World Health Organization.

Because of a lack of timely medical follow-up, on November 6, 2018, the patient's condition deteriorated, the size of the vegetation increased to $0.8 \times 2.5 \mathrm{~cm}$ (Fig. $1 \mathrm{~b})$ along with a hemorrhage that occurred on the gingiva, and a hemorrhagic spot formed on both lower limbs. An echocardiogram confirmed the presence of severe regurgitation. Additionally, the left atrium and ventricle were enlarged, and the left ventricular ejection fraction was $64 \%$. The blood test results showed that the platelet level dropped rapidly over time, reaching its lowest level at $29 \times 10^{9} / \mathrm{L}$ on November 6, 2018 (see Additional file 1). The MRI examination showed that both the second and third vertebra hyperplasia and abscess in the muscle increased significantly on November 19, 2018 (Fig. $2 \mathrm{~b}, \mathrm{~d})$. The antibiotics for brucellosis were changed to levofloxacin ( $400 \mathrm{mg} /$ dose, once daily), doxycycline (100 $\mathrm{mg} /$ dose, twice a day), and sulfamethoxazole tablets (600 $\mathrm{mg} /$ dose, once daily), and the patient was treated with medicines to enhance the platelet levels at the same time.

However, the patient's situation deteriorated again, and heart failure was discovered on October 22, 2019. The size of the vegetation was $1.3 \times 1.5 \mathrm{~cm}$ (Fig. 1c). The left atrium and ventricle were further enlarged, and the left ventricular ejection fraction was $58 \%$. The enddiastolic volume (EDV) and end-systolic volume (ESV) of the left ventricular were $304 \mathrm{ml}$ and $105 \mathrm{ml}$, respectively. A strong regurgitation signal presented on the mitral valve, with a pulse rate of 67 beats/min. The fraction shortening (FS) value was $36 \%$. Although the platelet level had recovered to $52 \times 10^{9} / \mathrm{L}$, the hemoglobin level sharply decreased to $85 \mathrm{~g} / \mathrm{L}$ (see Additional file 1). The NT-proBNP levels reached $4152.0 \mathrm{pg} / \mathrm{mL}, 33$ times higher than the normal level. It is worth noting that the level of creatinine was normal, except on October 22,
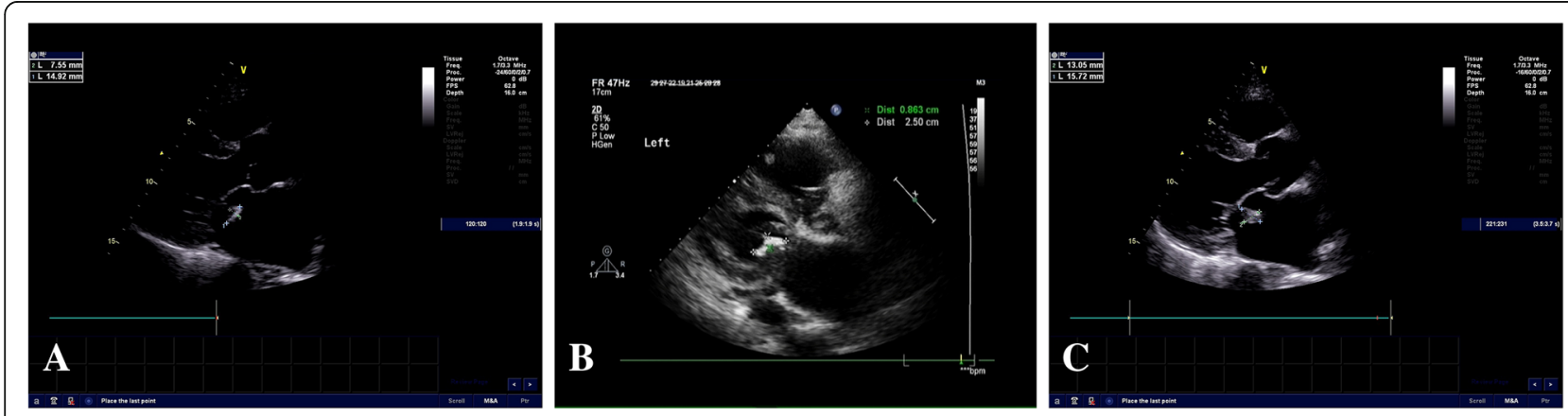

Fig. 1 Transesophageal echocardiography showing the vegetation (red arrow) on the posterior leaflet of the mitral valve at different times. a October 11, 2018; b November 6, 2018; c October 22, 2019 

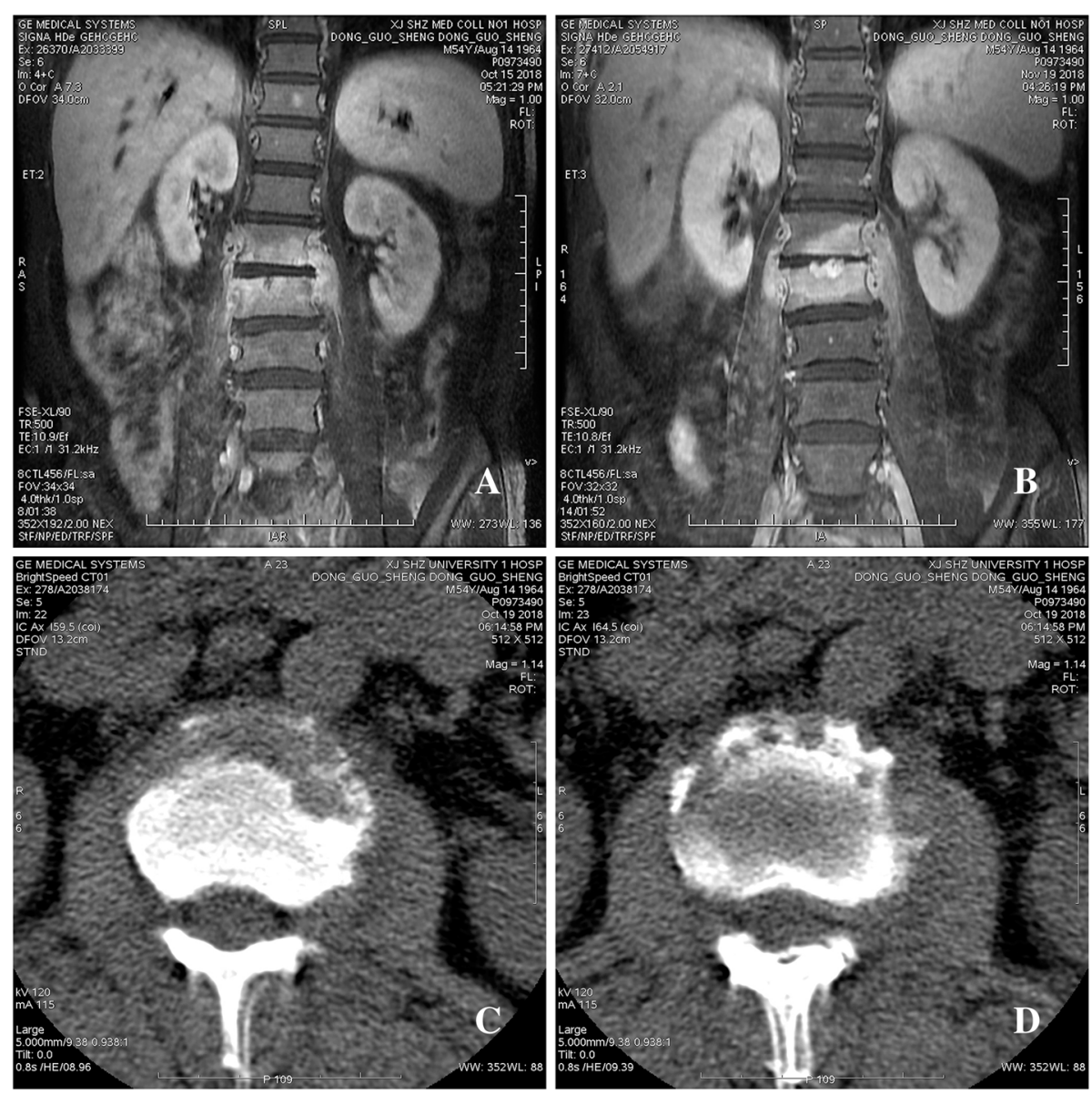

Fig. 2 The patient with Brucella spondylitis at L2-3. a-d The MRI and CT examinations showed the destruction of the vertebral bodies of $L 2-3$ at different times. a, b The MRI examination on October 15 and November 19, 2018. c, d The CT examination on October 15 and November 19 , 2018. The red arrows indicate abscess-formed area, and the green arrows indicate the hyperplasia-formed area

2019, when it reached its peak level at $252.6 \mathrm{umol} / \mathrm{L}$ (see Additional file 1). Additionally, the bone marrow aspiration result showed that the proliferation of bone marrow was considerably reduced, the granulocyte and erythrocytes were multiplicative, and the proportion of neutrophilic segmented granulocytes increased with the development of granulocyte lineage hyperplasia in the bone marrow (data not shown). At the moment of submission of this manuscript, the patient remains in bed at home because of severe debility caused by brucellosis. Now, the patient must undergo regular renal dialysis as a follow-up, and on June 26, 2020, the patient had renal dialysis. The clinical symptoms and diagnostic results at different times are listed in Additional file 1. The onset, diagnosis, and treatment of the disease in this patient are shown in Fig. 3.

\section{Serological tests}

The diagnosis of brucellosis was based on the rose bengal plate test (RBPT) and the SAT. The RBPT and SAT
Brucella antigen were purchased from the Institute of Infectious Disease of the China Centers for Disease Control and Prevention. The SAT result was 1:800.

\section{Pathogen isolation and identification}

Five milliliters of venous blood was collected from the patient on October 11, 2018 and October 22, 2019, and the blood samples were injected into a biphase blood culture and incubated at $37^{\circ} \mathrm{C}$ for 5 days. Conventional biological methods were used for the isolation and identification of the bacteria [4]. The minor phenotypic differences were used to distinguish the biovars of Brucella, including serotyping, phage typing, fuchsin and thionin dye sensitivity, $\mathrm{CO}_{2}$ requirement, $\mathrm{H}_{2} \mathrm{~S}$ production, and metabolic properties, and Brucella melitensis $16 \mathrm{M}$ was used as the reference strain. This process was completed at the Brucellosis Laboratory, the National Institute for Communicable Disease Control, and the Center for Disease Prevention and Control (CDC) of China in Beijing. 


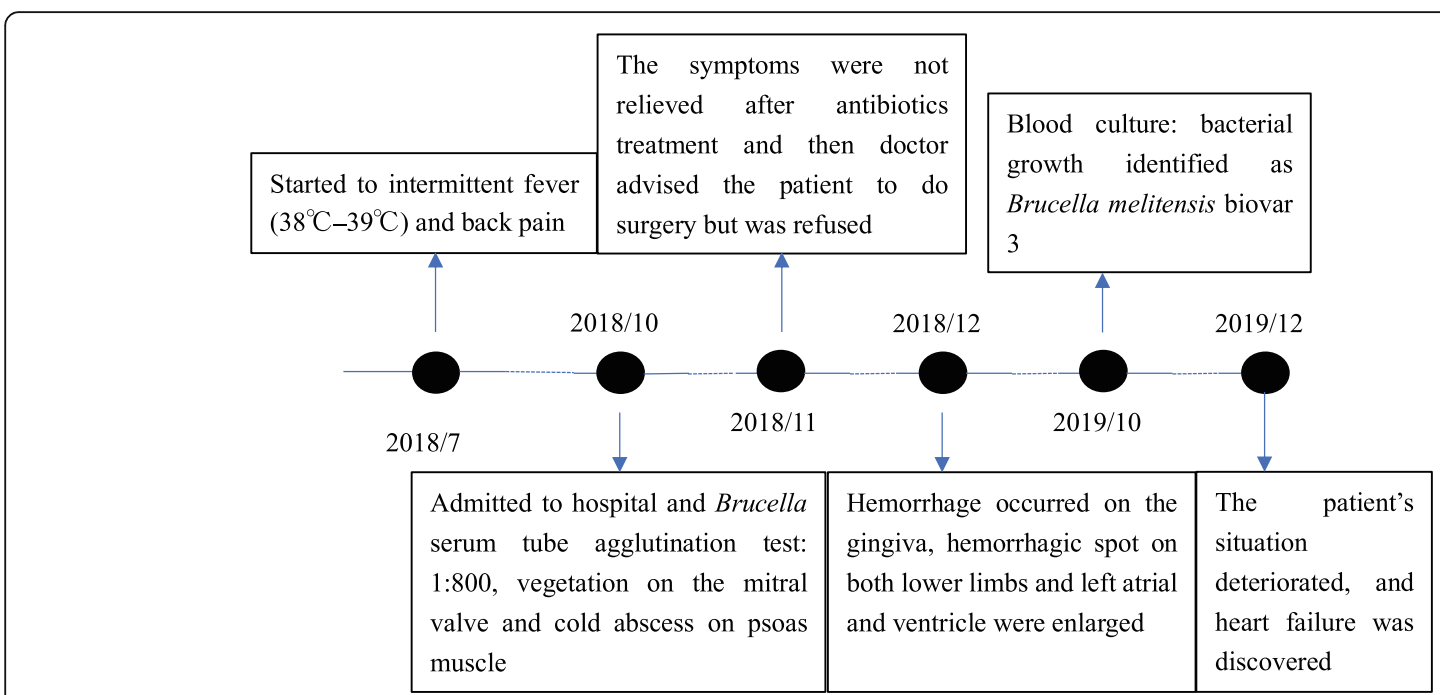

Fig. 3 The onset and outcome of the disease, diagnosis, and treatment

The specific sequences of the IS711 primers have been described in previous work [5]. The reaction system for the gene sequencing included $13 \mu \mathrm{L} \mathrm{dd}_{2} \mathrm{O}, 15 \mu \mathrm{L}$ master mix, $0.5 \mu \mathrm{L}$ of each primer, and $1.5 \mu \mathrm{L}$ of the DNA template. The amplification conditions were as follows: $95^{\circ} \mathrm{C}$ for $5 \mathrm{~min}, 30$ cycles at $95^{\circ} \mathrm{C}$ for $2 \mathrm{~min}, 55^{\circ} \mathrm{C}$ for 2 min, $72^{\circ} \mathrm{C}$ for $2 \mathrm{~min}$, and a final incubation at $72^{\circ} \mathrm{C}$ for $4 \mathrm{~min}$. The positive PCR products were purified using the TIAN-gel Mini Purification Kit (TIANGEN, Beijing, China) and sequenced by Sangon Biotech Co., Ltd. (Shanghai, China). R version 3.6.1 was used to construct the tree according to the packages "ggplot2," "ggtree" [6], and "colorspace." The DNA extractions were performed using a whole bacterial genome nucleic acid extraction kit [Tiangen Biotech (Beijing) Co., Ltd., Beijing, China]. The IS711 primers were synthesized by the Sangon Biotech Co., Ltd. (Beijing, China).

\section{Results}

\section{Bacterial isolation and identification}

The colonies of bacteria isolated from the patient's blood were semitransparent and round in shape, with smooth surfaces. Conventional biological identification showed the colonies to be short Gram-negative bacilli that did not produce $\mathrm{H}_{2} \mathrm{~S}$ and $\mathrm{CO}_{2}$. The urea, basic fuchsin, and thionin tests were positive. The $\mathrm{A}$ and $\mathrm{M}$ monospecific antisera agglutination and the bacteriophage $\mathrm{BK}_{2}$ test were positive. $\mathrm{The} \mathrm{Tb}, \mathrm{Wb}$, and $\mathrm{R} / \mathrm{C}$ phage typing tests were negative, suggesting that the colonies corresponded to the $B$. melitensis biovar 3 , an endemic strain in the XUAR $[5,7]$.

\section{Phylogenetic analysis}

A phylogenetic tree was constructed based on the 731 bp sequence of the IS711 repetitive element for the isolate. The nucleotide sequence from this study was deposited in the GeneBank database (IS711: MT846927). The phylogenetic analysis showed that the Brucella isolates in this study closely matched those of $B$. melitensis biovar 3 isolated from the Asia badger in Xinjiang, China (Fig. 4) [8].

\section{Discussion and conclusions}

Brucellosis is a worldwide zoonosis and systemic disease. The transmission to humans occurs primarily through contact with infected animals or the consumption of contaminated food such as raw milk and its byproduct [9]. Brucella infection cause lesions in any organ and system in the human body. The clinical symptoms of brucellosis include intermittent fever, night sweats, and joint and muscle pain [10]. The complications caused by brucellosis include osteoarticular, epididymal orchitis, nervous disorders, and liver involvement [11]. However, endocarditis combined spondylitis caused by Brucella is rarely reported. The incidence rate of endocarditis accounts for approximately only $2 \%$ of all brucellosis cases, but it is responsible for $80 \%$ of brucellosis-related mortality [12]. Jia et al. [13] studied $10 \mathrm{BE}$ cases and discovered a high death rate without the replacement of valves. In contrast, all of those who accepted prosthetic valve replacement surgery combined with at least 6 weeks of drug treatment survived and showed no relapse. Dourakis et al. [14] found that the implantation of the defibrillator itself could induce a case of BE. The patient recovered after the defibrillator was removed, and the pacemaker was explanted. In addition, the large vegetation was removed through surgery. Mahjoub et al. [15] studied infective endocarditis caused by Brucella. The patient showed a good prognosis after receiving a high dose of antibiotics and underwent surgery with 


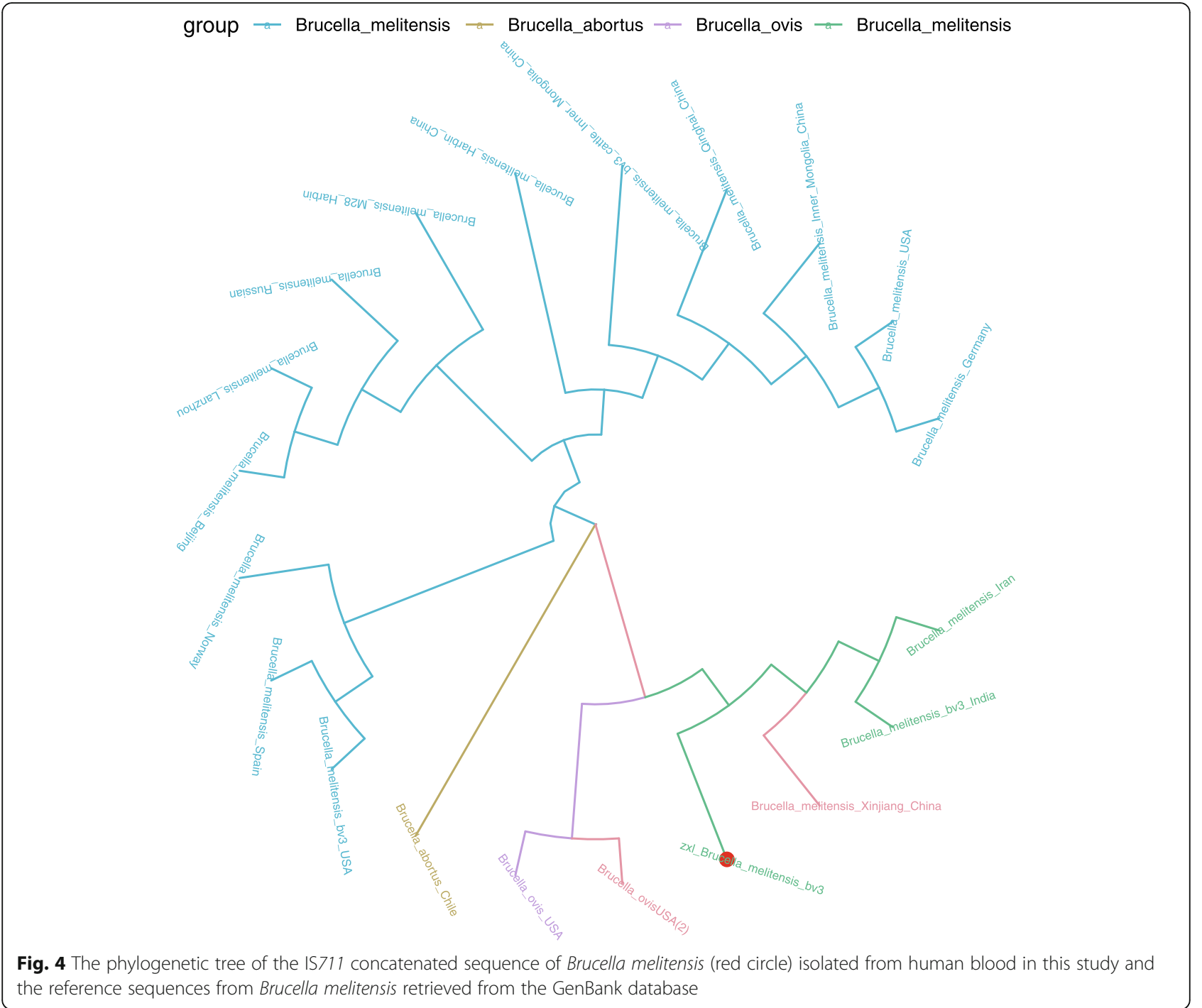

mitral valve replacement. It has been reported that the mortality rate of $\mathrm{BE}$ treated with a combination of antibiotics and surgery was $6.7 \%$, whereas that with antibiotic treatment only was $32.7 \%$ [16]. In our case report, the patient suffered brucellosis-induced endocarditis and spondylitis. However, because of financial constraints, the patient refused to undergo surgical treatment that might have improved his condition. Intriguingly, vegetation has been found in most BE cases. It has been reported that Brucella can often cause valvular lesions and cardiac insufficiency [17]. The reason why Brucella can cause vegetation on the valve is unknown.

Brucellosis can affect the entire vertebral column, and the lumbar spine is the most frequently involved vertebral region, followed by the thoracic and cervical segments $[18,19]$. It is well known that the multiple and contagious involvement of vertebral bodies occurs in tuberculous spondylodiscitis [20]. However, Brucella's involvement in numerous vertebral bodies has been described in only $9-20 \%$ cases [21]. The infection not only affects the vertebrae but also causes damage to neighboring tissues, including epidural and para-prevertebral tissues, psoas muscles, and radicles. Ulu-Kilic and colleagues [18] studied 293 patients with spinal brucellosis in Turkey, and psoas abscess only accounted for $3.4 \%$ (10) patients. In this study, hyperplasia occurred on the patient's second and third centrum, and a cold abscess formed on both sides of the psoas major muscles and the left side of erector spinae muscle. The thick abscess that formed in the psoas and spinae muscle suggested complicated BS according to the definitions [18].

The most common manifestations among $\mathrm{BE}$ or patients with BS are fever, sweating, backache, debility, spleen, and liver enlargement $[17,18]$. In this study, in addition to the symptoms mentioned previously, the patient suffered a hemorrhage on the gingiva, a hemorrhagic 
spot formed on the lower limbs, and even edema appeared when heart failure was discovered on October 22, 2019. Very few studies have reported such clinical symptoms before. Hence, it could be an atypical manifestation for the patient who suffered BE combined with BS.

$B$. abortus and B. melitensis are the most frequently isolated species from $\mathrm{BE}$ patients, but Brucella suis is rarely found (5\% of cases) $[15,17,22,23]$. B. melitensis causes more severe diseases associated with disabling complications [24]. Of note, B. melitensis is also the most predominant pathogen isolated from BS cases, with $61 \%$ biovar 3 isolates and $39 \%$ biovar 1 isolate [18, 2527]. In this study, the organism was also identified as $B$. melitensis biovar 3 , and this was consistent with previous studies where human and livestock brucellosis were primarily caused by $B$. melitensis biovar 3 in XUAR $[5,28]$. Interestingly, the Brucella isolates in this study closely matched the $B$. melitensis biovar 3 isolated from the Asia badger, which indicates that the Asia badger is a Brucella spillover host that infects sheep or cattle and then acts as a reservoir host, and this poses a massive threat to livestock and humans [8].

For those with brucellosis endocarditis and spondylitis, drug treatment combined with surgery is the best approach, especially for patients with severe endocarditis and spondylitis. However, surgery is the last option for treating BS [29]. Maryam [16] reported that the mortality rate of $\mathrm{BE}$ with drugs combined with surgical treatment was $6.7 \%$, but the drug treatment solely was $32.7 \%$. There is no consensus for treating BE and BS. Patients are typically given doxycycline and rifampicin with or without aminoglycoside [30, 31].

Alternatively, it has been reported that streptomycin combined with doxycycline has superior efficacy and lower relapse rates than other treatments [27, 32]. The duration of antibiotic therapy in patients is adjusted according to the clinical manifestation. In addition, financial constraints, health care system-related differences, and follow-up are important factors that affect a patient's treatment. In this study, the patient was not a local resident and his medical insurance did not cover the Shihezi health care system. Hence, the local government could only provide a partial subsidy for the patient's medical costs according to health care system regulations. However, the patient still refused to undergo surgery due to financial constraints. In addition, timely follow-up was not able to be obtained, which might be another reason for the deterioration of the patient's condition. These situations may be present for some patients; hence, they cannot be ignored in the treatment.

In summary, this is the first reported case of endocarditis combined with spondylitis caused by $B$. melitensis biovar 3 isolated from a shepherd in China. Brucellosis infection can cause work-power losses because of misdiagnosis or lack of proper treatment. Although there is no standard therapy protocol for treating BE and BS, early diagnosis and treatment are essential for a successful outcome.

\section{Supplementary Information}

The online version contains supplementary material available at https://doi. org/10.1186/s12879-021-06142-3.

Additional file 1: Table S1. Clinical and laboratory data of the patient with Brucella endocarditis and spondylitis.

\section{Acknowledgments}

We thank LetPub (www.letpub.com) for its linguistic assistance during the preparation of this manuscript.

\section{Authors' contributions}

$H Z, Y-L W, X-L Z$, and $J-H Y$ performed the majority of the pathogen detection, coordinated all work related to the study, performed the data analysis, drafted the manuscript, and participated in the design of the study; S-S X, B-J L, and Q L collected the case clinical data; X-Y D and Z $W$ performed the phylogenetic tree construction and participated in the data analysis; Y-Z W, B-Y C, and C-F C conceived and designed the study and revised the manuscript. All authors have read and approved of the final manuscript.

\section{Funding}

This study was supported in part by grants from the National Key Research \& Development Plan (U1803236, 37160020, 2017AA003, 32002245, 2017YFD0500304, and 2018ZX10101002-007), the State Key Laboratory of Veterinary Etiological Biology (SKLVEB2017KEKT009), the Non-profit Central Research Institute Fund of Chinese Academy of Medical Sciences (2020PT330-003), and the International Scientific and Technological Cooperation in Bingtuan (2016AH001). The National Key Research \& Development Plan (U1803236, 37160020, 2017AA003, 32002245, 2017YFD0500304, and 2018ZX10101002-007) supported the data collection and analysis, the State Key Laboratory of Veterinary Etiological Biology (SKLVEB2017KEKT009) and the Non-profit Central Research Institute Fund of Chinese Academy of Medical Sciences (2020-PT330-003) supported the pathogen isolation and identification, the International Scientific and Technological Cooperation in Bingtuan (2016AH001) supported the edit of the manuscript.

\section{Availability of data and materials}

All of the data generated or analyzed in this study are included in this published article.

\section{Declarations}

Ethics approval and consent to participate

The Ethics Committee of the First Affiliated Hospital of Shihezi University approved the study.

\section{Consent for publication}

The patient agreed the publication of the data in this study and provided a written informed agreement.

\section{Competing interests}

The authors declare that they have no competing interests.

\section{Author details}

${ }^{1}$ School of Animal Science and Technology, Shihezi University, Shihezi City 832000, Xinjiang, China. ${ }^{2} \mathrm{NHC}$ Key Laboratory of Prevention and Treatment of Central Asia High Incidence Diseases, Shihezi City 832000, Xinjiang, China. ${ }^{3}$ The First Affiliated Hospital of Shihezi University, Shihezi City 832000, Xinjiang, China. ${ }^{4}$ State Key Laboratory for Infectious Disease Prevention and Control, Collaborative Innovation Center for Diagnosis and Treatment of Infectious Diseases, National Institute for Communicable Disease Control and 
Prevention, Chinese Center for Disease Prevention and Control, Beijing 100050, China. ${ }^{5}$ School of Medicine, Shihezi University, Shihezi City 832000, Xinjiang, China.

Received: 6 January 2021 Accepted: 5 May 2021

Published online: 20 May 2021

\section{References}

1. Goonaratna C. Brucellosis in humans and animals. Ceylon Med J. 2009;52(2): 66. https://doi.org/10.4038/cmj.v52i2.1028.

2. Zormpala A, Skopelitis E, Thanos L, Artinopoulos C, Sipsas NV. An unusual case of brucellar spondylitis involving both the cervical and lumbar spine. Clin Imaging. 2000;24(5):273-5. https://doi.org/10.1016/ S0899-7071(00)00226-6.

3. Zhong Z, Yu S, Wang X, Dong S, Xu J, Wang Y, et al. Human brucellosis in the people's republic of China during 2005-2010. Int J Infect Dis. 2013;17(5): e289-e92. https://doi.org/10.1016/j.ijid.2012.12.030.

4. Xiao DLGS, Wang DL, Wang JQ, Li TF, Cui BY, et al. Brucellosis control manual. Beijing: Beijing People's Medical Publishing House; 2008. p. 17-29.

5. Zhang $H$, Shengnan $S$, Benben $W$, Jiang $Y$, Wenxing W, Fei $G$, et al. Brucella melitensis isolated from aborted cow and sheep fetuses in northwest of China. Kafkas Üniversitesi Veteriner Fakültesi Dergisi. 2018;24(2)307-10.

6. Yu G, Lam TT, Zhu H, Guan Y. Two methods for mapping and visualizing associated data on phylogeny using Ggtree. Mol Biol Evol. 2018;35(12): 3041-3. https://doi.org/10.1093/molbev/msy194.

7. Zhang H, Benben W, Jihai Y, Zhen W, Zhang J, Yuanzhi W, et al. Brucella suis S2 isolated from aborted sheep fetuses in northwestern China. Kafkas Universitesi Veteriner Fakultesi Dergisi. 2019;25(6):869-72.

8. Liu X, Yang M, Song S, Liu G, Zhao S, Liu G, et al. Brucella melitensis in Asian badgers, northwestern China. Emerg Infect Dis. 2020;26(4):804-6. https://doi.org/10.3201/eid2604.190833.

9. Voelker CDCPSER. Brucella in raw Milk prompts health warning in Texas Jama. 2017. https://doi.org/10.1001/jama.2017.15338.

10. Yang HX, Feng J-J, Zhang Q-X, Hao R-E, Yao S-X, Zhao R, et al. A case report of spontaneous abortion caused by Brucella melitensis biovar 3. Infect Dis Poverty. 2018;7(1):31. https://doi.org/10.1186/s40249-018-0411-X.

11. Jia B, Zhang F, Ying L, Zhang W, Li J, Zhang Y, et al. The clinical features of 590 patients with brucellosis in Xinjiang, China with the emphasis on the treatment of complications. PLoS Negl Trop Dis. 2017;11(5):e0005577.

12. Dean AS, Crump L, Greter H, Hattendorf J, Schelling E, Zinsstag J, et al. Clinical manifestations of human brucellosis: a systematic review and metaanalysis. PLoS Negl Trop Dis. 2012;6(12):e1929. https://doi.org/10.1371/journa l.pntd.0001929.

13. Jia B, Zhang F, Pang P, Zhang T, Zheng R, Zhang W, et al. Brucella endocarditis: clinical features and treatment outcomes of 10 cases from Xinjiang, China. J Infect. 2017;74(5):512-4. https://doi.org/10.1016/j.jinf.2017. 01.011.

14. Dourakis S, Sambatakou H, Tsiachris D, Kittou N, Alexopoulou A, Archimandritis A. A 70-year-old stock-breeder with tricuspid valve and defibrillator lead brucella endocarditis. Int J Cardiol. 2008;126(3):e47-e49.

15. Mahjoub M, Hassine M, Boussaada M, Ben Messaoud M, Cheniti G. Brucellosis as an unusual cause of mitral infective endocarditis. J Cardiol Curr Res. 2016;5(1):00149.

16. Keshtkarjahromi M, Razavi SM, Gholamin S, Keshtkarjahromi M, Hossain M, Sajadi M. Medical vs. medical and surgical treatment for brucella endocarditis: a review of the literature. Ann Thorac Surg. 2012:94(6):2141.

17. Koruk ST, Erdem H, Koruk I, Erbay AE, Tezer-Tekce Y, Erbay AR, et al. Management of Brucella endocarditis: results of the Gulhane study. Int J Antimicrob Agents. 2012;40(2):145-50. https://doi.org/10.1016/j.jjantimicag.2 012.04.009.

18. Ulu-Kilic A, Karakas A, Erdem H, Turker T, Alabay S. Update on treatment options for spinal brucellosis. Clin Microbiol Infect. 2014;20(2). https://doi. org/10.1111/1469-0691.12351.

19. Yang $X$, Zhang $Q$, Guo $X$. Value of magnetic resonance imaging in brucellar spondylodiscitis. La Radiologia Medica. 2014;119(12):928-33. https://doi. org/10.1007/s11547-014-0416-x

20. Pourbagher A, Pourbagher MA, Savas L, Turunc T, Demiroglu YZ, Erol I, et al. Epidemiologic, clinical, and imaging findings in brucellosis patients with osteoarticular involvement. AJR Am J Roentgenol. 2006:187(4):873-80. https://doi.org/10.2214/AJR.05.1088
21. Erdem H, Elaldi N, Batirel A, Aliyu S, Sengoz G, et al. Comparison of brucellar and tuberculous spondylodiscitis patients: results of the multicenter "Backbone-1 study". Spine J. 2015;15(12):2509-17.

22. Dourakis S, Sambatakou H, Tsiachris D, Kittou N, Alexopoulou A Archimandritis A. A 70-year-old stock-breeder with tricuspid valve and defibrillator lead brucella endocarditis. Int J Cardiol. 2008;126(3):e47-e9. https://doi.org/10.1016/j.ijcard.2007.01.018.

23. Wasl Al-Adsani AA, Al-Mousa M. A case of Brucella melitensis endocarditis in a patient with cardiovascular implantable electronic device. Infect Drug Resist. 2018;11:387-90. https://doi.org/10.2147/IDR.S152771.

24. Shawky HA. Brucella endocarditis: heart views; 2006.

25. Colmenero JD, Cisneros JM, Orjuela DL, Pachón J, Juarez C. Clinical course and prognosis of Brucella spondylitis. Infection. 1992;20(1):38-42. https://doi. org/10.1007/BF01704893.

26. Liang C, Wei W, Liang X, De E, Zheng B. Spinal brucellosis in Hulunbuir, China, 2011-2016. Infect Drug Resist. 2019;12:1565-71. https://doi.org/10.214 7/IDR.S202440.

27. Ulu-Kilic A, Sayar MS, Tütüncü E, et al. Complicated brucellar spondylodiscitis: experience from an endemic area. Rheumatol Int. 2013: 33(11):2909-12. https://doi.org/10.1007/s00296-012-2555-5.

28. Yang $X$, Yan H, Wang N, Li Y, Bie P, Zang J, et al. Whole-genome sequencing of Brucella melitensis from Xinjiang provides insights into its genetic features. Pak Vet J. 2017;37(3):251-6

29. Alp E, Doganay M. Current therapeutic strategy in spinal brucellosis. Int J Infect Dis. 2008;12(6):573-7. https://doi.org/10.1016/j.jijid.2008.03.014.

30. Jiao L-D, Chu C-B, Kumar CJ, Cui J, Wang X-L, Wu L-Y, et al. Clinical and laboratory findings of nonacute Neurobrucellosis. Chin Med J. 2015;128(13): 1831-3. https://doi.org/10.4103/0366-6999.159362.

31. Tarfarosh SFA, Manzoor M. Neurological manifestations of brucellosis in an Indian population. Cureus. 2016,8(7).https://doi.org/10.7759/cureus.684.

32. Ariza J, Bosilkovski M, Cascio A, Colmenero J, Corbel M, Falagas M, et al. Perspectives for the treatment of brucellosis in the 21st century: the loannina recommendations. PLoS Med. 2007;4(12):e317. https://doi.org/1 0.1371/journal.pmed.0040317.

\section{Publisher's Note}

Springer Nature remains neutral with regard to jurisdictional claims in published maps and institutional affiliations.
Ready to submit your research? Choose BMC and benefit from:

- fast, convenient online submission

- thorough peer review by experienced researchers in your field

- rapid publication on acceptance

- support for research data, including large and complex data types

- gold Open Access which fosters wider collaboration and increased citations

- maximum visibility for your research: over $100 \mathrm{M}$ website views per year

At $\mathrm{BMC}$, research is always in progress.

Learn more biomedcentral.com/submissions 